\title{
DIGITALIZATION AS AN ENABLER OF BUSINESS MODEL DYNAMICS
}

\author{
Mariana Tesařová $^{1}$, Aleš Krmela ${ }^{2}$, Iveta Šimberová ${ }^{3}$ \\ Faculty of Business and Management, Brno University of Technology, \\ Kolejni 2906/4, 61200 Brno, Czech Republic \\ E-mails: ${ }^{1}$ mariana.tesarova@vut.cz; ${ }^{2}$ ales.krmela@vut.cz (corresponding author); ${ }^{3}$ simberova@fbm.vutbr.cz
}

Received 29 February 2020; accepted 06 May 2020

\begin{abstract}
The purpose of the article is to answer a research question related to the extent of the impact of digitalization on a business model (BM) of a focal company. An original primary, qualitative research has been conducted. It draws on multiple, in-depth case studies on a globally active B2B incumbent manufacturing companies that recently implemented a digital platform-based customer relationship management system. The data were gathered through participative observation and semi-structured interviews with system users and project leaders. The contribution of the research is in linking the business model dynamic change with a customer relationship management system (CRMS). It identifies the element HOW - value creation - as the mainly affected element of BM of the focal company.
\end{abstract}

Keywords: customer relationship management, digitalization, business model dynamics, manufacturing companies, B2B.

JEL Classification: L21, L22, L61, O14, O31, O32, O33.

\section{Introduction}

Digitization transforms the companies and the ways they do the business (Witschel et al., 2019). The 21 st century can be called a digital era. A trend that started rather slowly in the second half of the 20th century has gained momentum in the 21 st century with never seen before the speed of changes. Companies not only transfer analog data to digital (digitization), which is being currently seen as an imperative (Witschel et al., 2019). In the second step, companies start to use digital data for business decisions (digitalization). Digitalization became event an enabler of new BMs (Förster et al., 2019). Finally, digital transformation restructures industries, thus introducing new ways of bringing products and services to the consumers (Rachlinger et al., 2019). The perceived or latent consumer needs are satisfied in new ways; a new customer experience leads to new sources of revenue. Improved relationships with customers, employee satisfaction, optimized resource utilization help companies achieve success (Rachlinger et al., 2019). Large, incumbent companies, in order to cope with the challenges, seek ways how to adapt their BMs to the new reality. One of the ways is to digitalize their processes, both for internal and external uses through the implementation of customer relationship management sys- tem (CRMS), employing digitized data (GilGomez et al., 2020). While the CRMS on a digital the platform is by far not a new tool as such, its impact on the BM of both the focal company and $\mathrm{BM}$ of its customers does not seem to be well researched (ibid.).

Among scholarly literature, there is a perceived gap "...in the knowledge of how incumbents can systematically and successfully engage in business model change" (Witschel et al., 2019, p. 1027). Amining for closing this gap, the below introduced research focused on the understanding of how and to what extent the digitalization embodied in CRMS affects the extant BM of B2B incumbent manufacturing companies. The BM change can be of a different scope and intensity. The initial assumption was that the CRMS would cause an incremental, dynamic adaptation of individual BM's elements, rather than a more radical change of the elements and the whole BM.

\section{Methods}

The identified research gap led to the research question: How does digitalization impact the BM of the focal company and eventually, the BMs of its customers?

For answering the research question, a descriptive-exploratory approach has been chosen and an in-depth case study has been conducted. 
A similar approach has been applied by e.g., Rachinger et al. (2019). A case study approach is suitable for studying a contemporary phenomenon in a natural environment (Yin, 2018).

A globally acting European manufacturing company, active in the field of biomaterials (Company A) has been identified as a suitable research object. The company introduced recently a Customer Relationship Management System (CRMS) on a digital, cloud platform. Given the long tradition of the company, its global outreach, number of internal and external employees, as well as the number of customers, it can be considered an "unusual" case that the company did not have yet a software-based CRMS. In parallel, the company can be considered a "usual" in terms of its size, the role in the industry and the business activities it conducts. This combined with longitudinal access to the object not only justifies but even encourages the selection of the company (Yin, 2018).

The main research method applied in the case of A was a participative observation. Various internal project-related documents like user manuals, presentations, instructions have been analyzed. The triangulation of findings was reached through a combination of both semi-structured and nonstructured interviews with CRMS implementation project team, CRMS key users as well as with regular users of CRMS.

Aiming for increasing the validity and generalizability of the findings, a second case study on another European, a globally active manufacturing company, active in the field of polymers (Company B), has been conducted. The approach to CRMS, the expectations of both companies, the efforts needed for implementation have been compared.

In the case of $\mathrm{B}$, a semi-structured interview with a project head and a member of a project implementation team, being in parallel, also a key user of the CRMS tool, has been performed.

While the company A had no previous structured experience with CRMS, company B had. B has decided to replace its previous CRMS with a new one. This provided for a possibility to compare the approach of both, otherwise similar, companies.

Both companies have been chosen purposively for numerous further reasons. Mainly, the research team could get a deeper insight that would not be otherwise accessible to other research teams. It is an established practice that the companies do not like to communicate about their particular CRMS as both cases confirmed. Exceptional- ly, good access to both companies has been granted to the research team.

Both companies are globally active, having a comparable size (nine-digit EUR annual turnover, several thousands of employees in total), being $\mathrm{B} 2 \mathrm{~B}$, incumbent manufacturing companies. Both companies are from German-speaking area. This gives an extra interesting insight into the implementation of the comparable digital tool within a similar cultural and language environment. Both $\mathrm{A}$ and $\mathrm{B}$ implemented the CRMS nearly in parallel in terms of time.

The key difference between A and B was the full novelty of the CRMS for A vs. previous experience with CRMS in case of $\mathrm{B}$. Further, while A implemented the CRMS group-wide, in case of B, the CRMS was implemented only in one operating company. This is another key difference between both cases.

In both cases of $\mathrm{A}$ and $\mathrm{B}$, the performed semistructured interviews were recorded and transcribed. The non-structured interviews were transcribed only.

The two of the interviewed responders (one from each company) have a deep previous knowledge of CRMS and experience with its implementation in other companies. Thus, they have brought additional insight, enabling indirect, although non-structured comparison of the impact of CRMS on the BM of the focal companies and the $\mathrm{BM}$ of the customers of the focal companies.

The construct and the validity of the findings were reached through two key informants" review of the case study protocol.

For confidentiality reasons, the company names and the names of the respondents have been anonymized.

\section{Literature review}

\subsection{Business model}

In the conducted research, the BM is understood as a core logic of the company, an abstraction of how the company does the business (Osterwalder \& Pigneur, 2010). BM comprises of key building elements: WHO is the customer, WHAT is the value proposition, HOW is the value created and delivered and WHY being the value capture, the logic why the BM makes money, what is the profit mechanism, what is the costs structure, revenue streams (Gassmann et al., 2014; Osterwalder \& Pigneur, 2010; Teece, 2010). Similarly, Demil and Lecocq (2010) see BM consisting of resources and competences, organizational structure (including 
activity value chain and value network) as well as a value proposition.

Spieth and Schneider (2016) see the BM as a means to develop and commercialize opportunities. CRMS can play an essential role in capturing opportunities.

\subsection{Business model dynamics}

A static view of a BM is not sufficient for capturing the dynamic nature of both the company ecosystem and the focal organization in reaction to a changing environment. Gassmann et al. (2014) emphasize the dynamics among and inside the single elements of the BM in reaction to impulses coming both from inside and from the outside of the company. As an outcome, the content and the relative importance of the elements get modified, changed to a smaller or larger extent. The dynamics of the BM's elements means a certain degree of extant BM's adaptation, depending on the intensity of the impulses. Schaffer et al. (2019, p. 8) define the dynamic BM as ".. a complex system of interrelated subcomponents of the value creation, delivery, and capture mechanisms, which is interacting with heterogeneous internal and external influences leading to the evolution of its components and the system itself".

In an incremental form, the BM adapts moderately. In a more radical form, the dynamics can lead to a transformative innovation of BM. Wirtz (2016) identifies five levels of the BM transformation, which can also be understood as an adaptation, change, or modification of BM (terms being often used interchangeably). In a simple form, it can be of an adaptive, incremental nature - stabilization or evolutionary-adaptive, incrementallyradical adaptation in the form of extension or migration, and finally radically-innovative, thus disruptive to structures and industries. Particularly stabilization of BM, being a very weak adaptation of $\mathrm{BM}$, is typical for industries with low intensity of competition, low environmental changes, and the presence of players with similar market power (Wirtz, 2016).

Demil and Lecocq (2010) consider BM dynamics a critical ability for the long-term sustainability of the company. Gil-Gomez et al. (2020) emphasize the link between the sustainability of a company's BM supported by CRMS. It is considered a matter of survival that BMs adapt swiftly in reaction to the changing environment (Cosenz \& Noto, 2018). Simberová et al. (2018) recognize the $\mathrm{BM}$ dynamic as a critical aspect for value maximization for numerous external and internal stakeholders.

\subsection{Digitization - digitalization - digital transformation}

Several articles have been written about the differences among these three terms, yet they are still used almost interchangeably in the literature (Mergel et al., 2019), especially the first two digitization and digitalization (Savić, 2019). Digital transformation represents a newer term and is usually easily understood, even though it still causes semantic confusion. Digital transformation tries to shield both digitization and digitalization as its constituting components and seeing them as necessary steps in the big picture on the organization's path towards digital transformation (Savić, 2019). Digitization focuses on data conversion (Negroponte, 1995; Loebbecke \& Picot, 2015; Savić, 2019), the straightforward process of converting analog information to digital (Brennen \& Kreiss, 2014 Gobble, 2018). Digitalization is more about information processing, using digital technology and digitized information to create value in a new way (Gobble, 2018; Brennen \& Kreiss, 2014. Digital transformation builds on these two and focuses on the knowledge leveraging (Savić, 2019).

Even though there are several differences, terms like digitization, digitalization, or digital transformation are still used interchangeably in the literature (Mergel et al., 2019). In this the article, the digitalization and digital transformation is perceived in connection with the acceptance of technologies that result in increased productivity, value creation, and social prosperity, CRMS being one of them. Companies are slowly turning to holistic BMs, a complete redesign of their products and services while at the same time creating long-term relationships with their suppliers and customers (Duarte, 2015; Ebert \& Duarte, 2016). Furtherly, digital transformation represents a continuous change process that is technology-driven. Such a process influences both companies and the entire society. In other words, there is no digitalization and digital transformation without software (Ebert $\&$ Duarte, 2018). Companies react to these changes and gradually implement principles of digitalization into the key elements of their BMs.

\subsection{Customer relationship management system (CRMS)}

Due to the rapid evolvement of CRMS technologies, businesses can furtherly deepen and nourish relationships with their customers (Trepper, 2000). According to Kotler and Keller (2006), CRMS is defined as a process of managing de- 
tailed information about each customer individually and then carefully managing all the customer trigger points. This process aims to maximize customer loyalty. CRMS effectively collects, translates, and analyses information about the customer. Information is then used for decisionmaking purposes (Rajput et al., 2018; Ernst et al., 2011). CRMS represents the approach for gathering, examining, understanding and translating information that is connected to customers and furtherly transform this information into managerial action (Rajput et al., 2018). By acquiring information about customers, companies can design their products according to customer needs (Reinartz et al., 2004). CRMS brings together technology, people, and firm capabilities while ensuring the connectivity between them (Jain et al., 2014). Nowadays, CRMS represents strategy and technology that has become a vital element in the modern economy (Nikolić et al., 2014).

CRMS is a tool that is designed to capture communication and processes with external subjects, namely with potential or with existing customers. CRMS recognizes three categories: A lead, a prospect, and a customer. A lead is an unspecified contact who has not yet qualified as a potential customer. A prospect is a potential customer who meets certain criteria to become a real customer (Lilyquist, 2019). But, the prospect does not yet buy. Finally, the customer already has an active business relationship with the focal company.

\section{Digitalization at A through CRMS}

A is a Europe based manufacturing company, active in biomaterials. It employs a few thousand employees and reaches high, nine-digit millions of EUR annual revenues. It was established more than 100 years ago and was growing steadily since then.

The fast growth of the company has exposed the company, its executives, managers, and employees numerous management related challenges. The transition from originally local, later regional, to current global company has brought both lots of opportunities and challenges at the same time. It was a mix of different cultures that had to be managed. It was a mix of different management and leadership styles established in the acquired companies. It was a different quality of available information received both from the operations and from the market. Especially since every single acquired new operating company (OPCOs) was running its own enterprise resource planning (ERP) systems, with numerous local supporting applications. Typically, these were incompatible with the established systems running in A.

With time, managing the entire group without the support of comparable performance data, available within a reasonable time in the needed quality, became a difficult task that consumed a lot of resources, esp. human, time and financial. As the company has grown further, it became more and more difficult to properly coordinate the market, customer, and product development related activities across and between the OPCOs, BFs, as well as external offices. Frequently, it happened that one OPCO was contacted by an existing or potential customer of another OPCO, without both OPCOs finding that properly out and acting in a harmonized way. Similarly, if a customer of one BF was interested in products from the other BF, A had difficulties to handle that in terms of proper information flow. Accordingly, it happened again and again that two OPCOs worked independently on the same customer projects, did quote different business terms and conditions like prices, delivery terms, payment terms, and similar to the same customer. A certain customer's dissatisfaction was pre-programmed. Or, on the contrary, the customer might have benefited out of it by picking the cheaper from the both, otherwise comparable, offered options. Naturally, the management of A, whenever finding out about it, was not very amused.

Inside the OPCOs and $\mathrm{BFs}$, it was also rather challenging to keep proper records on the evolution of the business relationships with the existing customers and business potential coming from various new prospects. If particularly thanks to the ERP system in place, key customer-related information like master data, orders, and shipment statistics were available, anything that was around predeceasing to the order or as a follow-up, was much more fragmented and not so well recorded, documented and traceable. The majority of the data was available in a fragmented way in single employees' computers in the form of emails, MS Word, MS Excel, MS PowerPoint documents, every now and then shared in an unstructured manner with the rest of the team. This turned to be an issue not only for daily regular business but particularly when employees were out of the office, when coming and leaving the company or when a comprehensive business status information was needed for various reasons.

Accordingly, the board has decided to introduce a proper, cloud-based customer relationship management system (CRMS). 
The decision about the specific software the platform has been taken after evaluation, together with the core project team and with future CRMS key users, numerous on the market available options. A has decided for renting rather than buying the software. The core implementation team started to work, together with the key users, on matching the design of the solution of A's specific needs, considering both the $\mathrm{A}$ as a group, as well as individual specifics of single BFs. These individual specifics turned out to be to a surprising extent distinct. The harmonization of expectations was done with the core key user working group, which included people from all OPCOs and BFs. Coordination with presidents of BFs was essential for acceptance of the CRMS on all management levels.

The main task of the key users was to codesign the CRMS, learn it to a max. possible extent and later train the local users in the single BFs. Presumably, approx. 5\% of the total, A staff was future direct local users of the CRMS tool. All key users involved in the implementation phase (total of 20 people) participated in the project alongside their daily tasks. The implementation costs and efforts included mainly the working time of all involved persons, both external and internal. The core team met at least five or six times for periods of 1-3 days, to both fine-tune and learn to work with the system. The project manager and the core implementation team (three persons) spent 50$60 \%$ of their entire working time with the project. Since the core project team gathered regularly physically, those were also traveling costs, and of course, the external cost for the consultancy company. Finally, it took more than two years from the initiation of the idea until the go-live of the CRMS.

Impacted areas of A were company services and departments that are typically in direct touch with the customers. These areas were the main users and, at the same time, the main beneficiaries of the CRMS. The key users from these departments co-created the CRMS, which certainly improved the internal acceptance of the system. It was obvious that there will be not only benefits but also some burdens in the form of extra initial efforts of the users, esp. in the transition stage, but possibly also afterward. In the form of data transfer before and after the implementation (contacts, essential documents like price lists), as well as in for of keeping proper records in needed quality inside the CRMS when using it daily.

\section{Digitalization at $B$ through CRMS}

$\mathrm{B}$ is a Europe based, B2B incumbent manufacturing company, active in the field of processing of polymers used in the construction industry. It has over 80 years of tradition. Its annual turnover is approx. a middle nine-digit mill EUR with a few thousands of employees. It comprises of two dozen of OPCOs, based both in Europa and overseas. The company is to a large extent, vertically integrated. Some OPCOs sell up to 50\% of their output internally to their sister companies, who process the product and sell polymerbased solutions further. The OPCOs is in fact to a large extent independent companies, under an umbrella of a larger group. The group shows a high degree of decentralized organization.

One of the OPCO, being in turnover approx. $20 \%$ and in terms of employees approx. $10 \%$ of the total group, selling approx. 50\% of its output to external customers, have used CRMS in the past. Around 2017, alongside with an upgrade of its ERP system, it has decided to upgrade its CRMS system, too. The main driving force behind the decision was the management of the OPCO who intended to enhance the quality of customer communication and its internal transparency. In parallel, also numerous existing CRMS users in the OPC have recognized and indicated a need for a change. The previous system did not correspond to the requirements of a modern CRMS tool, particularly in terms of its interlinkage with the ERP system (management of the master data, availability of sales statistics and similar). The upgrade was planned only for the particular OPCO, not for the entire group. The aim was to improve user experience and to reach a better link between ERP and CRMS in terms of the transfer of various customer and order relevant data between both through improved automation of the transfer.

A CRMS key project team consisting of five internal members and one external consultancy company was established back in 2017. A CRMS was intended for a total of 30 internal users, all from both front and back office (sales managers, customer service team).

It took nearly two years, approx. 1600 hours spent on implementation, out of it $25 \%$ spent by the project leader. B has spent approx. EUR 250.000 for obtaining the base module software, including external implementation costs. Internal implementation efforts were measured mainly through the working hours spent. All members of the implementation team participated in the project alongside their other daily tasks. 
B has decided to go-live in a step-by-step approach, installing the base module first while waiting with the installation of additional supporting modules (e.g., a module allowing working off-line or a module allowing higher automatization of the external communication with multiple customers).

$B$ is now running the new CRMS for several months, and the internal feedback is positive.

\section{Results and discussion}

An in-depth case study was conducted on A. The simplified case study of B was conducted mainly for comparison purposes, aiming for capturing the commonalities and the differences in both cases. Therefore, the below description of BM and its dynamic adaptation focuses in detail primarily on $\mathrm{A}$.

The original A's BM before the CRM implementation:

- BM Element WHO (customer): B2B customers worldwide, typically medium to large B2B companies, acting either locally, regionally or globally.

- BM Element WHAT (value proposition): Biobased products serving typically as an intermediate product for further processing and manufacturing of consumer goods. Tailor-made, quality products, with a focus on service, timely shipments, good availability. A's philosophy is a stable business, good predictability, dependability, mid- to long term strategic cooperation with the key customers. A sees it valuable to have good proximity to its customers.

- BM Element HOW (value creation and delivery): The customers are in direct touch with single business areas or OPCOs of $\mathrm{A}$. The bigger customers have a dedicated account manager, who executes a coordinating function, however, it does not serve as a single point of contact.

- The communication ways between A are rather short, flexible, thus contributing to faster reactions, better understanding, and swift problem-solving.

- BM Element WHY (value capture): The customers pay for ownership of the product. The product costs are kept competitive mainly thanks to efficient production and maximization of time utilization of manufacturing equipment, optimisation of the energy and raw materials usage, all in all through well-balanced costs structure.
A significant portion of the items is on the same initial product platform, while tailored to customer's specific needs short before completion to the customers' exact specifications. Larger lots of the same product can be run, thus reducing the amount of time and material losses pertinent to the product change on the manufacturing machines. It allows for higher supply flexibility and better product availability. The finished goods stocks can be kept lower, thus having a positive impact on the net-working capital and A's better economic performance.

The CRMS was not implemented with an explicit, expressed aim of adapting the extant BM of $\mathrm{A}$, at least not towards the external world. It was seen more as an opportunity for internal process improvement. Terms like lack of information, individualism, multiple tools, and difficult follow-up were mentioned in the context of the present situation, indicating a process and performance improvement need.

However, soon it became obvious that the single elements of the extant BM were somewhat affected by the implementation of CRMS. A's managers admit that the assessment of the exact impact of CRMS on the company and its BM is based more on soft facts, guesses and gut feelings, rather than on hard metrics. Not all CRMS processes running can be properly and reliably measured or compared quantitatively with the previous processes. The tracking of both the historical and the current data (e.g., time spent) is missing.

A's BM after the CRMS implementation:

- BM Element WHO (customer): A feels to be able to capture better its potential customers, so-called prospects. These are companies, which are not yet actively buying; however, they have expressed an interest in future cooperation. Yet, they are not part of the ERP system. Likely, some of the prospects in the past did not turn into active customers for a simple reason of lack of proper records, insufficient communication, or follow up due to non-existent supporting tools. CRMS enables that due to build-in reminders. The cross-company more efficient information exchange on the latest status and the possibility to link various customer projects improves the probability of linking a customer of one $\mathrm{BF}$ to a product of another BF. The WHO does not change. 
- BM Element WHAT (value proposition): A expects to be able to become towards the external world "more A" rather than "a bunch of OPCOs and BFs belonging to A". In other words, the customers will see A more like as one entity, they will consider it more as a complex solution provider. A brand will become more valuable and the credibility of A towards its customers will increase. The customers presumably perceive the cooperation with A as a more convenient and a professional one. The WHAT gets incrementally, silently, and dynamically adapted.

- BM Element HOW (value creation and delivery): Through more efficient communication internally and externally, value is created for the customers by being able to react faster and in a higher quality to prospects or customer inquiries and requests. There is no need for company employees for the asking there and back, across the own organization, or even the customer, what has been done so far, what is the current status. The prospect or the customer gets faster served. Particularly, CRMS supports in case of market projects going across various OPCOs and BFs.

- BM Element WHY (value capture): Presumably less internal time and efforts are needed for gathering information about customer history and current status. Be it the time needed to train new team members, hand over an account from one hand to another, prepare for the meetings with customers or preparation of customerrelated reports. The information is available on-line, in real-time, via cloud system, anywhere where there is access to www. This is seen by the internal teams as a major advantage versus the past. The WHY gets incrementally, dynamically adapted in both positive and negative (extra costs) direction.

On the other side, some drawbacks exist, too. Mainly the sales teams are yet concerned about being exposed to extra work, particularly in terms of recording the customer-related communication and data in new, more administratively demanding and time-consuming ways. However, since CRMS was installed just recently, it is believed that with time and experience, this drawback will disappear as the employees get used to working with it. Accordingly, both the CRMS users and the company managers are convinced that this is just a temporary issue.

A negative impact on value capture came from the implementation costs (one time) and the running costs (license fee and maintenance). However, particularly the latter was not perceived as critical since the CRMS software is not too difficult to manage and maintain, while the license fee is marginal given the company revenues.

Also the HOW gets incrementally, dynamically adapted, and improved.

The main challenges for the organization were seen in the transition phase. It was a cultural change, moving from the basic office applications used for years or even decades as a storage for the majority of customer-related information to an online, cloud-based tool. More administrative work was expected, particularly on the sales managers' side. When working on new potential business cases, instead of writing a quick email with a quotation, they have to convert it all in a quite structured way into the CRMS. Instead of just keeping the business cards in a folder, every single one needs to be uploaded, using a dedicated application, into the system. Instead of writing a few lines of customer meeting reports, a structured one has to be written, filling all fields in the CRMS. Certainly, it may be partially just a matter of going out of the comfort zones of individual CRMS users, leaving old habits behind and moving to the new way of working. On the other hand, it may sound simple for doing that once in a while, in a quieter time. But, if that has to be done during two weeks of a business trip with dozens of meetings, it can be rather time-consuming and it can lead to stress and discomfort.

In summary, the company managers see more pros than cons in the system. Especially BFs presidents became very enthusiastic about the CRMS. They recognize that it is mainly A's internal organization benefiting from the CRMS. The customer benefit, too, however, their BMs have impacted too much smaller extent if impacted at all.

The hard metrics and KPIs for measuring the efficiency of the CRMS and comparing it with the past performance have not been set. Company managers admit that there are numerous perceptions and assumptions about the benefits of CRMS. Although the digitalization through CRMS is perceived as very important, the evaluation of its specific, tangible, measurable benefits in the form of return on investment remains in the examined cases of two B2B companies, a possible future challenge. Currently, neither A nor B intends to implement any specific metrics for measuring return 
on investment, time savings or similar. On the other hand, the CRMS installed enables a simple future to follow up on many prospects, new business cases, won or lost opportunities. Something that was not possible to exactly follow up in the past due to lack of the availability of structured information.

\section{A comparison of $A$ and $B$}

Key aspects of both cases in common: B2B, incumbent, manufacturing, Europe based. Ninedigit EUR annual turnover, several thousands of employees.

Both A and B admit that they do not intend to measure return on investment. They see it problematic to use reliable metrics that would provide quality, usable data. Both see CRMS as a way to improve the internal transparency, internal communication related to customers as a way to improve the quality of the information provided, recorded, and stored. Both believe that CRMS creates a value inside their BMs through improved quality of working for and with the prospects and the customers. This implicitly improves the BM element WHAT - value proposition. However, the improved value proposition is not communicated explicitly towards the external world. In parallel, the enhancement of BM element WHY - value capture is intangible. None of both companies can quantify how much extra business, new customers, new opportunities, projects have been gained specifically thanks to CRMS. But both companies achieved to make these processes more transparent.

Key differences between $A$ and $B$ case: Product and customer are completely different. A includes several BFs. Although all A's products are based on biomaterials, the markets of the single BFs are not overlapping. B consist of several OP$\mathrm{COs}$, who act relatively independently. Some of the OPCOs are in a direct business relation (supplier-customer), while the portion of such a business reaches up to $50 \%$, thus significant.

A has decided to implement CRMS groupwide, while B has implemented a one OPCO's individual CRMS. A is licensing the system, while B has acquired the ownership.

A has devoted significantly relative fewer human resources for the core project team in terms vs. the total number of employees (A: $0.1 \%, \mathrm{~B}$ : $2 \%$ ). A has also nominated $10 \%$ of the key users vs. total users, while B has nominated $20 \%$. In the case of $\mathrm{B}$, the project team members were at the same time, also the key users, which was not the case with A.
An initial outcome in the case of both companies showed an incremental, dynamic adaptation of the original $\mathrm{BM}$ and its elements thus leading to a minor adaptation of the existing BM. None of the key elements of the extant BM has been changed radically, and the BMs remained in its core logic unchanged.

\section{Conclusions}

The contribution of the conducted study is in the explicit interlinking of $\mathrm{BM}$, its dynamic through adaptation of individual BM's elements and the CRMS. The study highlights the CRMS being an enabler of the dynamic BM adaptation. At the same time, it demonstrates that the resulting level of dynamic adaptation of BM of the focal company is minor, incremental.

The study focused on a specific way of making the business of manufacturing, B2B traditional, incumbent companies, more digital. The key interest area was the impact of the digitalization through CRMS on the extant BM of the focal company. Company A did move from a de-facto analog customer-related data management system in the form of basic office software-based information storage and exchange, to a more sophisticated, cloud-based CRMS solution. Company B, on the contrary, moved to a more sophisticated CRMS, compared to the previous one. Both companies not only digitized but also digitalized, i.e., it started using the digitally available data actively for steering of the customer-related processes and business.

Three of the four elements of BMs of the subject companies are somewhat affected by CRMS implementation and use. Both $\mathrm{A}$ and $\mathrm{B}$ admit that precise quantification of the impact is not possible. It is even not intended. But both A and B are firmly convinced that they are, after the implementation of the CRMS better companies than they have been before the CRMS. Better companies for their customer directly related employees, and better for their customers.

The extant BMs of both companies adapt just incrementally as a whole. BM's element WHO does not in fact change, although the company can presumably capture more business opportunities by turning more prospects (potential customers) into real customers. Although, the customers are acquired primarily from the same market. CRMS supports easier turning prospects of one $\mathrm{BF}$ into customers of another BF. This is enabled mainly by easier traceability of the history provided by the logic of CRMS. But in fact, the logic of the ele- 
ment "who is the customer" does not change through the CRMS.

The BM's element value capture (WHY) presumably adapts through more efficient internal and external communication, thus saving time, efforts and sometimes patience of the internal and external teams. In result, the efficiency improves, and some more business can be captured through improving the information flow when moving from the prospect to the customer phase, through better tracking and follow up of the activities like sampling and quotations. Also, here, an exact quantification is not possible due to lack of historical data and missing metrics.

This goes hand in hand with BM's element value creation and delivery (HOW) through an improved information flow, faster reaction times, generally less uncertainty or even less chaos and confusion, thus less dissatisfaction.

Last but not least, customers can be better and more efficiently served, which improves their comfort. Thus, the focal company is perceived as a more professional one. Thus, the BM's key element WHAT - the value proposition improves, too.

Even in the absence of the measurable hard data, the respondents from both companies have evaluated the most impacted elements of the BM ( 1 - the most, 4 - the least impacted): 1 . WHY value capture, 2 . HOW - value creation and delivery, 3. WHAT - Value proposition. 4. WHO - the customer.

The study concludes by stating that digitalization through the implementation of a CRMS in the examined cases contributes to an incremental, dynamic adaptation of the single elements of a BM. It does get dynamically adapted in a continuous process, rather than abruptly, radically changed. The main beneficiaries of the adaptation are the focal company's internal teams and functions. The BMs of external customers are impacted much less. Indirectly, it seems to be the element HOW - value capture of the customer's BM, partially benefiting from CRMS. Mainly in the form of more efficient communication with both $\mathrm{A}$ and $\mathrm{B}$.

A consultation with two CRMS experienced project managers, participating in $\mathrm{A}$ and $\mathrm{B}$ cases and involved in similar projects in other manufacturing B2B traditional companies has led to the confirmation of the study findings and conclusions. Therefore, there is a reason to believe that the findings can be generalized also beyond the subject case.

The conducted study is useful for scholars while examining the CRMS through the lens of a
BM. It concretizes the CRMS impact on the single elements of BM.

Since both $\mathrm{A}$ and $\mathrm{B}$ have implemented the CRMS relatively recently, a longer time evaluation of customer satisfaction could not be included. A longitudinal approach would provide a further understanding of the impact of CRMS on the BM of both A and B. Analysing the performance of both companies in two to three years from now, using e.g., an employee satisfaction or customer satisfaction surveys prior and post would be a good indicator of the success of CRMS. Although value creation and value capture are not well directly measurable, the results of such a survey could serve as an indirect indicator.

The research included two B2B incumbent large manufacturing companies. Despite good access to the research team to the cases and deep insight view, it can be seen as a limitation to generalizability. Further research could include a wider sample of manufacturing companies either from $\mathrm{B} 2 \mathrm{~B}$ or B2C fields. A comparison of the impact of CRMS on BMs of particularly B2C companies of a similar size would provide valuable insight regarding the differences or similarities between these two fields.

\section{Funding}

This work was supported by the Specific project "The concept of business management and development in an environment of multidisciplinary value creation networks" [FP-S20-6355].

\section{Disclosure statement}

Authors declare that they do not have any competing financial, professional, or personal interests from other parties.

\section{References}

Brennen, S., \& Kreiss, D. (2014). Digitalization and digitization.

http://culturedigitally.org/2014/09/digitalizationand-digitization

Cosenz, F., \& Noto, G. (2018). A dynamic business modelling approach to design and experiment new business venture strategies. Long Range Planning, $51,127-140$. https://doi.org/10.1016/j.lrp.2017.07.001

Demil, B., \& Lecocq, X. (2010). Business model evolution: In search of dynamic consistency. Long Range Planning, 43, 227-246. https://doi.org/10.1016/j.lrp.2010.02.004 
Duarte, C. H. C. (2015). Patterns of cooperative technology development and transfer for softwareengineering-in-the-large. In 2015 IEEE/ACM $2^{\text {nd }}$ International Workshop on Software Engineering Research and Industrial Practice (pp. 32-38). IEEE. https://doi.org/ 10.1109/SERIP.2015.14

Ebert, C., \& Duarte, C. H. C. (2016). Requirements engineering for the digital transformation: Industry panel. In 2016 IEEE $24^{\text {th }}$ International Requirements Engineering Conference (RE) (pp.4-5). IEEE. https://doi.org/10.1109/RE.2016.21

Ebert, C., \& Duarte, C. H. C. (2018). Digital transformation. IEEE Software, 35(4), 16-21. https://doi.org/ 10.1109/MS.2018.2801537

Ernst, H., Hoyer, W. D., Krafft, M., \& Krieger, K. (2011). Customer relationship management and company performance - the mediating role of new product performance. Journal of the Academy of Marketing Science, 39(2), 290-306. https://doi.org/10.1007/s11747-010-0194-5

Förster, M., Bansemir, B., \& Roth, A. (2019). Understanding the role of data for innovating business models: A system dynamics perspective. In Wirtschaftsinformatik 2019 Proceedings. https://aisel.aisnet.org/wi2019/track14/papers/3/

Gassmann, O., Frankenberger, K., \& Csik, M. (2014). The business model navigator, 55 models that will revolutionise your business. Pearson (ePub). https://doi.org/10.3139/9783446437654.003

Gil-Gomez, H., Guerola-Navarro, V., OltraBadenes, R., \& Lozano-Quolis, J. A. (2020). Customer relationship management: digital transformatin and sustainable business model innovation. Economic Research-Ekonomska Istraživanja, 1-18.

https://doi.org/10.1080/1331677X.2019.1676283

Gobble, M. M. (2018). Digitalization, digitization, and innovation. Research-Technology Management, 61(4), 56-59.

https://doi.org/10.1080/08956308.2018.1471280

Jain, T., Chauhan, S., \& Sharma, R. (2014). Customer relationship management CRM and performance. International Journal of Research, 1(11), 425-428. https://pdfs.semanticscholar.org/f322/c218e4daead 6f75024a301d4279ed4d7d712.pdf

Kotler, P., \& Keller, K. L. (2006). Marketing management $\left(11^{\text {th }}\right.$ ed.). Prentice-Hall.

Lilyquist, M. (2019). What is a Prospect vs. a Lead? https://www.thebalancesmb.com/marketing-salesprospect-1794386

Loebbecke, C., \& Picot, A. (2015). Reflections on societal and business model transformation arising from digitization and big data analytics: A research agenda. Journal of Strategic Information Systems, 24(3), 149-157. https://doi.org/10.1016/j.jsis.2015.08.002

Mergel, I., Edelmann, N., \& Haug, N. (2019). Defining digital transformation: Results from expert inter- views. Government Information Quarterly, 36(4), 101385. https://doi.org/10.1016/j.giq.2019.06.002

Negroponte, N. (1995). Being digital. Vintage Books.

Nikolić, D. M., Stanković, M. A., \& Simić, N. D. (2014). CRM as a management tool for improving services. Journal of Process Management. New Technologies, 2(1), 81-90.

http://www.japmnt.com/images/Volume 2/Issue 1/CRM AS A MANAGEMENT TOOL FOR IMPROVING SERVICES.pdf

Osterwalder, A., \& Pigneur, Y. (2010). Business model generation. A handbook for visionaries, game changers, and challengers. John Wiley \& Sons, Inc.

Rachinger, M., Rauter, R., Müller, C., Vorraber, W., \& Schirgi, E. (2019). Digitalization and its influence on business model innovation. Journal of Manufacturing Technology Management, 30(8), 1143-1160. https://doi.org/10.1108/JMTM-01-20180020

Rajput, A., Zahid, M. M., \& Najaf, R. (2018). Using CRM to model firm performance in a business-tobusiness market. Journal of Relationship Marketing, 17(2), 118-151. https://doi.org/10.1080/15332667.2018.1440142

Reinartz,W., Krafft, M., \& Hoyer, W. D. (2004). The customer relationship management process: Its measurement and impact on performance. Journal of Marketing Research, 41(3), 293-305. https://doi.org/10.1509/jmkr.41.3.293.35991

Savić, D. (2019). From digitization, through digitalization, to digital transformation. Online Searcher, 43(1), 36-39.

http://www.infotoday.com/OnlineSearcher/Articles /Features/From-Digitization-Through-

Digitalization-to-Digital-Transformation129664.shtml

Schaffer, N., Pfaff, M, \& Krcmar, H. (2019). Dynamic business models: A comprehensive classification of literature. In MCIS 2019 Proceedings. 13. https://aisel.aisnet.org/mcis2019/13

Simberova, I., Krmela, A., \& Kita, P. (2018). Sustainable innovation of industrial companies. In $10^{\text {th }} \mathrm{In}$ ternational Scientific Conference "Business and Management 2018”, 3-4 May 2018. Vilnius, Lithuania. https://doi.org/10.3846/bm.2018.18

Spieth, P., \& Schneider, S. (2016). Business model innovativeness: Designing a formative measure for business model innovation. Journal of Business Economic, 86, 671-696. https://doi.org/10.1007/s11573-015-0794-0

Teece, D. J. (2010). Business models, business strategy and innovation. Long Range Planning, 43(2-3), $172-194$. https://doi.org/10.1016/j.lrp.2009.007.003

Trepper, C. (2000). Match your CRM tool to your business model. Information Week, 15(786), 74. 
https://www.researchgate.net/publication/3135738 66_Match_your_CRM_tool_to_your_business_mo del

Wirtz, B. W. (2016). Business model management design process instruments (2 ed.). Speyer.

Witschel, D., Döhla, A., Kaiser, M., Vogt, K.-I., \& Pletschinger, T. (2019). Riding on the wave of digitization: Insights how and under what settings dynamic capabilities facilitate digital-driven business model change. Journal of Business Economics, 89(8-9), 1023-1095. https://doi.org/10.1007/s11573-019-00950-5

Yin, R. (2018). Case study research and applications. Design and methods (6 ed.). Sage. 